\title{
The new Civil Procedure Rules. 2. Part 35 provisions and their implications
}

\author{
Keith Rix
}

The previous article (Rix, 2000) in this series described the process of dispute resolution and litigation under the new Civil Procedure Rules, which have now been implemented in England and Wales following the recommendations of Lord Woolf. The purpose of this article is to provide detail of the provisions of 'Part 35: Experts and Assessors' and examine the accompanying practice direction, the pre-action protocols, the 'Draft Protocol of Best Practice in the Instruction and Use of Experts' and the 'Draft Code of Guidance for Experts and Assessors' as they relate to the role of the medical expert.

\section{Fees and costs}

At the pre-action stage the cost of a report from an agreed expert is usually paid by the instructing first party.

Once proceedings have been issued, in order for the court to ensure that the costs of the litigation are proportional to the value of the claim, it needs to know what the cost of the expert's opinion is likely to be. It is not sufficient to quote an hourly rate as the court needs to know what the likely cost will be in order to decide whether or not such expenditure is justified in order to deal with the case justly. As well as quoting an hourly rate, experts might be advised to make an analysis of the fees that they have charged in different sorts of case so that in negotiating the fee those instructing the expert can be advised of the range of fees and the average charged in similar cases to that in which it is proposed to instruct the expert. However, the court may limit the amount of the expert's fees and expenses that the party who wishes to rely on the expert may recover from any other party, and whether or not an expert is paid above the limit depends on a contract with the instructing party as to the payment of the balance, even though it will not be recovered in the costs. Perhaps only insurance companies and well-funded parties in high-value claims will be prepared to agree such conditions.

Experts need to beware of failing to comply with court directions and deadlines. Wasted costs orders can be made by the court not only against parties to the action but also against third parties whom the court judges to have added to the costs or to have delayed the case by failing to meet their obligations. An expert who fails without good reason to prepare his or her report within the specified period of time, answer questions put to him within the specified time or comply with some particular order of the court runs the risk of having a wasted costs order made against him or even being discredited as an expert.

Although solicitors are allowed to work on a conditional fee basis - 'no win, no fee' - it is not acceptable for experts to work on this basis. It is contrary to the ethical codes of the Expert Witness Institute and the Academy of Experts, and the Draft Code of Guidance for Experts states that:

\footnotetext{
"Payments contingent upon the nature of the expert evidence given in legal proceedings, or upon the outcome of a case, must not be offered or accepted
}

Dr Keith Rix is a consultant forensic psychiatrist in the Leeds Community and Mental Health Services Teaching NHS Trust (High Royds Hospital, Menston, Ilkley, West Yorkshire LS29 6AQ) and a visiting consultant psychiatrist at HM Prison, Leeds. He is also a Member of the Academy of Experts and a founding Member of the Expert Witness Institute. 
because to do otherwise might contravene the expert's overriding duty to the court."

There has already been one case in the Commercial Court (Sesa Goa and A/S Bulk E Silimna, unreported, 1997) in which a judge indicated how such an arrangement might affect the court's evaluation of expert evidence:

“...it seems to me that the evidence given by an expert witness clearly has to be evaluated having regard to all circumstances relating to the expert and the weight that may be given to an expert's evidence may in some cases be affected by the fact that he is giving evidence under, or subject to, an arrangement which involves contingent fees. I therefore propose to adopt the practice in this court - and whether judges will do so, I do not know - that if an expert witness is called and Counsel does not ask the witness whether he is being remunerated on a contingent fee basis, the court will do so."

\section{The single joint expert}

The practice direction for Part 35 states that where possible, matters requiring expert evidence should be dealt with by a single expert. The aim is for the parties to agree as to who the expert should be. If they cannot agree the judge may select an expert from a list or direct the president of an appropriate professional body, such as the President of the Royal College of Psychiatrists, to identify a suitable expert.

Solicitors acting for claimants are likely to suggest the names of experts who are known to have prepared reports on behalf of claimants and defendants in the past. There is no reason why the parties should not agree to the appointment of an expert who has already acted as advisor at the pre-action stage.

Once appointed, each party can give instructions to the expert, which they must copy to the other party. It will be the norm for the parties to be jointly and severally liable for the expert's fees.

There is nothing to prevent a party to an action appointing an expert advisor to shadow the single joint expert and give advice on the expert's opinion and how the expert should be questioned if he or she gives oral evidence. However, such an advisor is not an expert within the meaning of the Rules, his or her fees are not included in the assessment of costs, he or she does not have to comply with the Rules and he or she needs to be insured for this work as he or she is not entitled to immunity from suit if it appears to those instructing him or her that his or her advice has been wrong. Since the court can limit what expert evidence is admitted, a party would need leave of the court to call such an advisor to give evidence, and it is difficult to imagine that such requests would be anything but extremely rare. Such 'shadow' experts would probably not be identified or known to the opposite party - they would probably not even be in attendance at court and they might be so much in the background that they would also be 'in the shadows'.

It is important to realise that the single joint expert is not a part of one or the other party's team. Thus, he or she has no private communication with either party. It is doubtful whether, as under the old Rules, he or she will be able to attend meetings with solicitors or conferences with counsel, unless perhaps with those for both or all parties, in which case he or she may be effectively cross-examined by counsel for both or all parties at the meeting.

\section{Written questions to experts}

Within 28 days of receiving the report, the parties to the action can put written questions to the expert for the purpose of clarification. There may be time limits for replying, perhaps within two weeks in fast-track cases and within four weeks in multi-track cases. The questions and answers are regarded as forming part of the expert's report.

If the expert fails to answer the question, the court can order that the party who instructed the expert may not rely on the expert's report and may not recover the expert's fees and expenses from any other party. Thus, if a party cannot rely on its expert's report or recover the cost of it, the party might seek to withhold the expert's fee!

If a party has not been allowed an expert, it may turn to an expert of its choosing on an advisory basis and ask the expert advisor what questions should be put to the jointly appointed expert.

The party or parties instructing the expert must pay any fees charged by the expert for answering questions.

\section{Content of reports}

The Rules require that: "the expert's report must state the substance of all material instructions, whether written or oral, on the basis of which the report is written".

At the end of an expert's report, the Rules require a statement that "a. the expert understands his or her duty to the court; and b. he has complied with that duty". 
The Rules also require the expert to include a 'statement of truth': "I believe that the facts stated in this report are true and that the opinions I have expressed are correct". Some experts have expressed reservations about this, particularly in relation to what the claimant tells the doctor. In psychiatric reports, where the opinion may depend considerably on self-reported symptoms which are not capable of objective verification, this may be a particular concern. If a claimant says that he or she is so anxious in cars that he or she cannot travel beyond the boundary of his or her own village, how is the psychiatrist to know whether or not this is a true fact? It is not necessary, indeed it cannot be possible, for the expert to know the truth behind everything he or she is told. However, if an expert has reason to know that something he or she is told is untrue, or there is good reason for doubt, then this information needs to be included. To do otherwise would not be in keeping with the spirit of these reforms. One suggestion for dealing with this issue is to include a statement at the beginning of the history section to the effect that this information has been provided by the claimant at the consultation. The fact that the claimant made such a statement is therefore true.

In addition, the Rules state that: "An expert's report must comply with the requirements set out in the relevant practice direction". The practice direction 'Experts and Assessors' incorporates some of the Rules, but it goes further. It indicates that the report should be addressed to the court and not to the party from whom the expert has received instructions. It also details the required contents of the expert's report (Box 1 ).

Psychiatrists who arrange for psychologists to carry out, score or interpret psychometric tests and incorporate their results or conclusions in their reports should take note of the requirements in relation to persons who have carried out tests or experiments for the expert.

The Draft Code of Guidance goes further than the Rules and the practice direction. It requires the expert to express any qualification of, or reservation regarding, his or her opinion. It lists a number of elements which should be included (Box 2). Experts who use the 'model report' (Torr, 1998; Rix, 1999) will find it easy to comply with the requirements. Again, the value of adapting the model report is obvious.

The Draft Code of Guidance also goes on to set out several guidelines for dealing with matters of fact and opinion (Box 3). It has not included some of the recommendations which were circulated for discussion in the draft protocol which has been superseded by the Draft Code of Guidance. They are nevertheless of value. They include a classification of facts and assumed facts (Box 4), which
Box 1. Contents of the expert's report required by the practice direction

Details of the expert's qualifications

Details of any literature or other material the expert has relied on in making the report

The identity of anyone who has carried out any test or experiment the expert has used for the report and whether or not the test or experiment has been carried out under the expert's supervision

The qualifications of the person who carried out any such test or experiment

Where there is a range of opinion on matters dealt with in the report: (a) a summary of the range of opinion; and (b) the reasons for the expert's own opinion

A summary of the conclusions reached

A statement that the expert understands his or her duty to the court and has complied with that duty

A statement setting out the substance of all material instructions (whether written or oral) and summarising the facts and instructions which are material to the opinions expressed in the report or upon which the opinions are based

Box 2. Contents of the expert's report required by the 'Draft Code of Guidance for Experts'

Academic and professional qualifications A statement of the source of instructions and the purpose of the advice or report

A chronology of the relevant events

A statement of the methodology used, in particular what laboratory or other tests (if any) were employed, by whom and under whose supervision

Details of the documents or any other evidence upon which any aspect of the advice or report is based

A statement setting out the summary of all instructions, whether written or oral, including a summary of the facts and instructions given to the expert which are material to the opinions expressed in the report or upon which those opinions are based

A declaration that the report has been prepared in accordance with the Code

A statement of truth 
Box 3. 'Draft Code of Guidance' requirements as to fact and opinion

In addressing questions of fact and opinion experts should keep the two separate and discrete

Where there is a conflict of factual evidence, experts

- should not express a view in favour of one or other competing set of facts, unless, because of their particular learning and experience, they perceive one set of facts as being improbable or less probable, in which case they may express that view, and should give reasons

- should express separate opinions on every set of facts in issue
Box 5. Useful recommendations as to report format from the draft pre-action protocol for experts

A stand-alone report which avoids cross referencing to external documents where possible

A concise style with text arranged in short sentences and paragraphs

Written in the first person singular and signed personally by the expert

Appendices used wherever the inclusion of material in the main body of the report would render it less clear

Conclusions given in the final section of the report before appendices and crossreferenced to the text which supports them should be clearly identified, and five points about the structure of the report (Box 5). Although there is no reference to the use of numbered paragraphs, cross-referencing to the body of the report from the 'conclusions', or what the practice direction requires in terms of a 'summary of conclusions', is obviously easier if paragraphs are numbered.

\section{Experts' discussions}

At any stage, the court may direct a discussion between experts for the purpose of requiring the experts to identify the issues in the proceedings and where possible, reach an agreement on an issue. The court may specify the issues which the experts must discuss and direct that following a discussion they must prepare a memorandum or statement for the court showing those issues on which they agree and those issues on which they

Box 4. Classification of the sources of statements of fact

Observed by the expert

Observed by others, stating whom

Contained in the instructions or documents supplied, identifying which

Assumed, stating on what basis

Inferred, stating the logic applied disagree and a summary of their reasons for disagreeing. The contents of the discussion shall not be referred to at the trial unless the parties agree. The parties are not bound to the agreement unless they expressly agree to be bound to it, so one or more of the experts might still find themselves giving evidence and being cross-examined on their agreed statement.

The Draft Code of Guidance suggests that a concise agenda should be produced through the cooperation of the parties, their lawyers and the experts reflecting the issues in the case on which the experts should give their opinions. It is recommended that it should be circulated 28 days before the date fixed for the discussion, be agreed seven days before the date fixed for the discussion, consist of questions which are clearly stated and apply to the case, where necessary, the correct legal test (e.g. the Bolam test in a case of alleged negligence) and consist of questions which are closed in nature, thus being capable of 'yes' and 'no' answers. Parties must not give and experts must not accept instructions not to reach agreement on areas which are within the experts' competence.

Failure to cooperate with other experts can have a draconian impact on the course of the litigation and on the expert's reputation. In the case of Stevens $v$. Gullis (Pile, third party) (1999), a building expert failed to cooperate in the preparation of a statement of agreement and disagreement. The Court of Appeal upheld the decision to debar him from being called as an expert witness on behalf of the defence and discredited him by stating that he had "no conception of the requirements placed on an expert under the 1998 Rules", he was "so discredited that it 
would be pointless for him to give evidence at all", and he was "not an appropriate person to give evidence in court having regard to his conduct". The parties were forced to resolve their dispute without his evidence and one wonders whether he managed to get payment of his fees from the aggrieved defendant.

\section{Applying to the court for directions}

Under the Rules, it is now possible for the expert to apply to the court for directions to assist him in carrying out his or her function as an expert. This should be in the form of a letter to the judge who is managing the case. He does not have to give notice to any party that he intends to apply, although it may be appropriate, indeed courteous, to do so. The judge's response may be to issue orders or directions to the parties.

It is not yet certain what circumstances would prompt an expert to apply to the court directly. One circumstance might be where the two parties have given conflicting instructions. For example, in a medical negligence case, where the claimant's partner or spouse is a witness to facts in the case, one party may ask that an assessment of the claimant's condition and prognosis should include taking a history from the partner or spouse, and the other party may say that there is to be no such consultation. Another circumstance might be in a personal injury case where the expert believes that particular documents, for example, papers filed in divorce proceedings, are essential to the consideration of matters of causation and one party is withholding these.

\section{Implications for the expert report}

Experts who use the model report will have no difficulty in giving details of their academic and professional qualifications. They should appear routinely as Appendix 1. Likewise, the model report has an appendix which can be used to give the details of any literature or other material on which the expert has relied.

The model report has a section in the Introduction, 'Summary of case'. This is probably the place in which to incorporate the substance of the instructions insofar as they relate to the facts and assumed facts of the case which are material to the opinions expressed in the report or upon which those instructions are based. It is not necessary to recount contents of the letter of instruction which are not material. It can be headed 'Summary of case and all material instructions'. Instructions as to the issues to be addressed go in the section 'Issues to be addressed'.

What may be new for many experts is the requirement, where there is a range of opinion, to summarise the range of opinion and give reasons for his or her own opinion. In a personal injury case where the psychiatric sequelae of an accident are at issue, the expert may form the opinion that most of the mental disorder is a result of events or circumstances unrelated to the accident but if the opinion might be reached that most is a result of the accident, he must say so and indicate why he or she prefers his or her own formulation.

The requirement that there should be "a summary of the conclusions reached" is again a feature of the model report. In the model report, this summary, rather like an executive summary in an official report, comes near the beginning, but there is no reason why the expert should not put it at the end or at the beginning and the end. It is easier for lawyers and judges to compare reports if they follow the same format.

The required statements are best incorporated in what is often called the 'Woolf Declaration'. A suggested version formed part of the previous article. Box 6 shows a further version which differs significantly in that, in order to comply with the Rule that reports should be addressed to the court, this is stated explicitly in the first paragraph. It has also been amended to conform with a version which has been approved by Sir Richard Scott, the Vice Chancellor.

For the purposes of this article, ordinary bold type has been employed to highlight statements which the Rules require the expert to make. Bold italic type, not in squared brackets, represents the rest of the declaration approved by the Vice Chancellor. Bold italic type in squared brackets has been employed for statements which reflect other requirements or recommendations arising from the Rules, the practice directions and the Draft Code of Guidance. In squared brackets in ordinary type are statements which may be included in order to cover more fully the role of the expert. The penultimate statement arises out of the advice of the Medical and Dental Defence Union of Scotland after an expert found that his report had been used to form the basis for a television programme (Griffiths, 1997)!

This is probably not the final word on the Declaration. Some of the expert witness bodies have 
Box 6. Declaration

I, Thomas Smeaton, declare that:

I understand that my duty included in my providing written reports and giving evidence is to help the court [on the matters within my expertise] and I confirm that I have complied with that duty. [This report is addressed to the court.]

[I have set out in my report what I understand from those instructing me to be the questions or issues in respect of which my opinion as an expert is required.]

I believe that the facts I have stated in this report are true and that the opinions I have expressed are correct. [All of the matters on which I have expressed an opinion lie within my field of expertise.]

I have endeavoured to include in my report those matters, which I have knowledge of or of which I have been made aware, that might adversely affect the validity of my opinion.

[Where there is a range of opinion on the matters with which the report deals, I have summarised the range of opinion and given reasons for my opinion.]

[I have stated the substance of all material instructions, whether written or oral, on the basis of which the report is written and] I have indicated the sources of all information I have used.

I have not without forming an independent view included or excluded anything which has been suggested to me by others (in particular my instructing solicitors).

[At the time of signing the report I consider that it is complete, accurate and mentions all matters that I believe are relevant to my expressed opinion.] I will notify those instructing me immediately and confirm in writing if, for any reason, my existing report requires any correction or qualification.

I understand that: my report, subject to any corrections before swearing as to its correctness, will form the evidence to be given \{under oath\}/\{upon affirmation\};

I may be cross-examined on the report by a cross-examiner assisted by an expert;

I am likely to be the subject of public adverse criticism by the judge if the court concludes that I have not taken reasonable care in trying to meet the standards set out above.

I confirm that I have not entered into any arrangement where the amount or payment of my fees is in any way dependent on (the opinion I have given or) the outcome of the case.

[This report is provided to those instructing me with the sole purpose of assisting the court in this particular case. It may not be used for any other purpose, nor may it be disclosed to any third party, without my express written authority.]

[This report has been prepared in accordance with the Draft Code of Guidance for Experts.]

published suggested declarations which differ slightly from this. The Society of Expert Witnesses believes that a lengthy and complex declaration is unnecessary. Its suggested declaration is limited to the part shown in ordinary bold type in Box 6. There is also a view that the declaration should be reviewed in each case and, if appropriate, modified according to the requirements of the case to which it relates.

Just as changes in the role and function of experts in child care cases are now reflected in some of the changes in the civil justice process, it remains to be seen whether or not the changes in the civil justice system will begin to affect the provision of expert evidence in the criminal courts and other tribunals of law.

\section{References}

Griffiths, J. R. (1997) Cautionary advice on expert reports. Summons (summer), 3.

Rix, K. J. B. (1999) Expert evidence and the courts. 2. Proposals for reform, the expert witness bodies and 'the model report'. Advances in Psychiatric Treatment, 5,154160 .

- (2000) The new Civil Procedure Rules. 1. The process of dispute resolution and litigation. Advances in Psychiatric Treatment, 6, 153-158.

Torr, J. (1998) The model form of medical expert's report. Expert, 3, 24.

Sesa Goa and A/S Bulk \& Silimna, 3 December 1997 (unreported).

Stevens v. Gullis (Pile third party), The Times, 6 October 1999. 


\section{Multiple choice questions}

\section{An expert's fees:}

a for replying to questions by the other party and arising out of his or her report will be borne by that other party

b which can be recovered from another party at the conclusion of the litigation may be limited by the court

c should not be negotiated on a conditional fee basis

d may be the subject of enquiry by the trial judge when the expert gives oral evidence

e where the expert is appointed as a single joint expert will be paid by the court.

2. The Civil Procedure Rules:

a require that the expert's report states the substance of all written material instructions on the basis of which the report is written

b require that the expert's report states the substance of all oral material instructions on the basis of which the report is written

$c$ are not binding on experts who provide advice at the pre-action stage

d do not permit wasted costs orders to be made against third parties

e allow parties 56 days following the receipt of an expert report to put questions to the expert for the purpose of clarification.

3. The 'Experts and Assessors' practice direction: a is binding on experts by virtue of the Civil Procedure Rule

$\mathrm{b}$ requires the expert to supervise anyone who carries out a test or experiment which the expert uses for the report c requires a statement setting out the substance of all material instructions whether or not they are material to the opinions expressed in the report or upon which the opinions are based

$\mathrm{d}$ requires that where there is a range of opinion on matters dealt with in the report, the expert should give a summary of the range of opinion

e requires the expert to include a curriculum vitae in or as an appendix to the report

4. The 'Draft Code of Guidance for Experts':

$\mathrm{a}$ is binding on experts by virtue of the Civil Procedure Rules

$b$ requires the expert report to include a chronological history of the matter

c requires the expert to ignore facts which may be inferred

$\mathrm{d}$ requires the expert report to be written in the third person

e where there is a conflict of evidence requires the expert to set aside his or her own preference for excluding one set of facts as being improbable or less probable.

\section{MCQ answers}

$\begin{array}{llll}1 & 2 & 3 & 4\end{array}$

a $F$ a $T$ a $T$ a $F$

$\begin{array}{llll}\text { b } T & \text { b } T & \text { b F } & \text { b } T\end{array}$

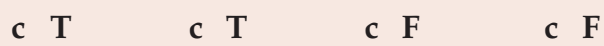

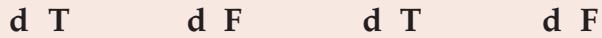

e

e $F$ 